\title{
ВЛИЯНИЕ СТИЛЯ ВОСПИТАНИЯ НА УРОВЕНЬ САМОРЕГУЛЯЦИИ ДЕТЕЙ ШКОЛЬНОГО И ПУБЕРТАТНОГО ВОЗРАСТОВ В ЗАМЕЩАЮЩИХ ПРАРОДИТЕЛЬСКИХ СЕМЬЯХ
}

\section{INFLUENCE OF THE EDUCATION STYLE ON THE LEVEL OF SELF-REGULATION OF CHILDREN OF SCHOOL AND PURBERTY AGE IN REPLACING FAMILY FAMILIES}

A. Svet

Summary: In this article we investigate the influence of the parenting style on the development of children self-regulation ability in foster grandparent families. The SQR questionnaire was used to identify the level of self-regulation of children and adolescents. Determination of the parenting style was carried out with application modified test of R.V. Ovcharova using a 5-point Likert scale for the answers. We used the questionnaire "Analysis of family relationships" by E.G. Eidemiller in two forms - for parents of children and adolescents in order to differentiate the relationship of parents with children of different ages and verify the results of the questionnaire by R.V. Ovcharova. A comparative analysis of the self-regulatory abilities is provided for children from complete, incomplete and grandparent substitute families with different styles of education. It is demonstrated that the average level of pupils selfregulation from grandparent families takes an intermediate position between the corresponding values of peers from full and single-parent families and corresponds to the low value. At the same time, the highest and lowest values of self-regulation levels are shown by children from authoritative full and liberal single-parent families, respectively. The differences in the self-regulatory ability depending on the gender of the child are demonstrated in families with an authoritative and liberal style of education.

Keywords: self regulation, parenting styles, replacing families, progenitor families.
$\mathrm{H}$ а сегодняшний день проблема развития саморегуляции у детей является областью активных исследований [1] - [4]. Согласно О.М. Вербиановой [5] саморегуляционная способность во многом определяется структурой семьи. Среди факторов, оказывающих отрицательное влияние на уровень саморегуляции детей, выделяют неполноту семьи и наличие старшей сестры у мальчиков. К положительным факторам относят такие составляющие как полнота семьи, наличие сиблинга одного пола, наличие старшего брата или сестры, участие в жизни семьи бабушек и дедушек. При этом вклад старшего поколения в воспитание детей определяется преимущественно видом родственных связей и ролью прародителей в семье [6].
Свет Анна Александровна аспирант, Московский государственный университет имени М.В. Ломоносова svetanna1911@gmail.com

Аннотация: В статье впервые исследуется влияние стиля воспитания на развитие саморегуляции детей школьного и пубертатного возрастов в замещающих прародительских семьях. Для выявления уровня саморегуляции детей и подростков использовалась SQR анкета. Определение стиля воспитания осуществлялось посредством модифицированного теста опросника P.B. Овчаровой с привлечением для ответов 5-балльной шкалы Лайкерта. Для дифференциации взаимоотношений родителей с воспитанниками различных возрастов и верификации результатов опросника Р.В.Овчаровой в работе применялся опросник “Анализ семейных взаимоотношений” Э.Г. Эйдемиллера в двух формах - для родителей детей и подростков. Произведен сравнительный анализ саморегулятивных способностей детей из полных, неполных и прародительских замещающих семей при различных стилях воспитания. Показано, что средний уровень саморегуляции воспитанников из прародительских семей занимает промежуточное положение между соответствующими значениями сверстников из полных и неполных семей и соответствует низкому значению. При этом самые высокие и низкие значения саморегуляции показали дети из авторитетных полных и либеральных неполных семей соответственно. Продемонстрированы различия саморегулятивной способности в зависимости от гендера ребенка при авторитетном и либеральном стиле воспитания.

Ключевые слова: саморегуляция, стили семейного воспитания, замещающие семьи, прародительские семьи.

Однако проблема воспитания детей в замещающих прародительских семьях изучена мало и требует детального рассмотрения. В связи с этим целью данной работы является исследование влияния стиля воспитания на уровень саморегуляции детей, воспитываемых только бабушкой и дедушкой.

Под стилем воспитания мы будем подразумевать совокупность взаимоотношений и поведения между родителями и детьми, а также психоэмоциональный семейный климат, посредством которого эти взаимоотношения отображаются. На сегодняшний день не существует единой классификации стилей семейного воспитания в зарубежной и отечественной литературе. 
Наиболее известная и распространенная классификация представлена Д. Баумринд, который выделяет 4 стиля семейного воспитания [7]: авторитетный, авторитарный, либеральный и безразличный. Такое разделение стилей основывается на различных степенях проявления требовательности и отзывчивости. Авторитетные родители характеризуются высокой требовательностью и отзывчивостью. Их методы являются напористыми, требующими выполнения четких правил и дисциплины, но в тоже время поддерживающими. Авторитарные родители характеризуются высокой требовательностью, но при этом низкой отзывчивостью. Они редко идут на уступки в отношениях и требуют от детей беспрекословного выполнения всех указаний. Таким родителям свойственен жесткий контроль над детьми и даже применение наказаний для выполнения поставленных задач. Либеральные родители характеризуются низкой требовательностью и высокой отзывчивостью. Им не удается установить строгий режим и дисциплину в семье, однако при этом они стараются удовлетворять потребности своих детей. Безразличные родители характеризуются не только низкой требовательностью, но и низкой отзывчивостью. В таких семьях у детей отсутствует выработанная система правил поведения и наблюдаются слабые способности к постановке и реализации целей.

Понятие саморегуляции в общем смысле может быть сформулировано как контроль над своими эмоциями и действиями. Американские исследователи В. Миллер и Дж. Браун [8] предлагают семиступенчатую модель саморегуляции. На первых этапах человек получает новую информацию и производит оценочные суждения о ней, сравнивая с личными стандартами и действующими нормами. Затем осуществляется деятельность, направленная на разработку и реализацию плана. На крайних этапах цикла происходит его оценка и при необходимости повторение с необходимыми коррекциями. В случае эффективности плана субъект демонстрирует значительный прогресс в достижении личных целей. Таким образом, саморегуляция является совокупностью множества сложных психоэмоциональных процессов и деятельности, работающих в неразрывной связи друг с другом.

Для выявления уровня саморегуляции участников эксперимента использовалась анкета SRQ (The SelfRegulation Questionnaire) [9]. Анкета SQR состоит из 63 вопросов, разделенных на 7 категорий. Каждая категория соответствует одному из этапов процесса саморегуляции:

1. получение актуальной информации;

2. оценка информации и сравнение ее с заданными нормами;

3. инициализация запуска изменений;

4. поиск вариантов действий;

5. составление плана;
6. реализация плана;

7. вынесение оценки об эффективности плана. Для ответов на вопросы анкеты использовалась психометрическая шкала Ликерта с выбором одного варианта из 5 градаций утверждений от “полностью согласен" до "полностью не согласен". Каждый ответ оценивался целым числом от 1 до 5 баллов. Расчет суммы $\Sigma$ полученных баллов за весь опросник позволял классифировать способность респондента к саморегуляции как высокую в случае $\Sigma>239$, среднюю $\Sigma=214$ - 238 или низкую при $\Sigma<213$.

Стиль семейного воспитания определялся посредством модифицированного теста-опросника Р.В. Овчаровой [10]. Для верификации теста Р.В. Овчаровой и дифференциации взаимоотношений с воспитанниками различных возрастов использовался опросник "Анализ семейных взаимоотношений" Э.Г. Эйдемиллера [11] в двух формах - для родителей детей и подростков.

Всего в заполнении анкеты SQR приняли участие 68 детей школьного (7 - 13 лет) и пубертатного (14 - 17 лет) периода развития со средним значением возраста $\mathrm{a}=12,6$ лет $(\mathrm{Da}=3,1)$. При этом гендерное распределение составило 35 девочек и 33 мальчика. Для заполнения анкеты по выявлению стиля воспитания был задействован только один воспитатель из каждой семьи, преимущественно женского пола. Для сравнения результатов уровня саморегуляции детей в различных семьях исследовались 13 замещающих прародительских, 19 полных и 12 неполных семей.

На первом этапе экспериментальной части работы исследовалось влияние стиля воспитания на уровень саморегуляции детей без гендерной дифференциации в замещающих прародительских, полных и неполных семьях. Средние значения суммы баллов, полученные детьми за заполнение SQR анкеты, показаны на рисунке 1а. Пунктирной линией отображено пороговое значение баллов среднего сред.=214 уровня саморегуляции. Из рисунка 1а видно, что средняя сумма баллов по результатам заполнения SQR анкеты выше в авторитетных семьях относительно авторитарных и либеральных, что свидетельствует о более высоком среднем уровне саморегуляции опрашиваемых. При переходе от авторитетного к авторитарному, и от авторитарного к либеральному стилю воспитания наблюдается уменьшение в каждом типе семей. Так в замещающих прародительских семьях средняя сумма баллов при авторитетном, авторитарном и либеральном стилях воспитания составляет $31=200 \pm 17,32=168 \pm 14$ и $33=164 \pm 12$ соответственно. При этом величины 31,32 и 33 соответствует низкому уровню саморегуляции. Для сравнения результатов отметим, что наивысший уровень саморегуляции - средний - демонстрируют дети из полных автори- 
тетных семей $п 1=220 \pm 5$, в то время как наименьшая саморегуляция наблюдается в либеральных неполных семьях л3 = $89 \pm 13$. Важно отметить, что при либеральном стиле воспитания опрашиваемые из замещающих прародительских семей показывают большую саморегуляционную способность 33 по сравнению с п3 = $139 \pm$ 7 в полных семьях.

Полученные данные говорят о том, что полнота семьи и стиль воспитания являются определяющими факторами развития саморегуляции детей. При этом прародители способны эффективно замещать родителей, что подтверждается сопоставимыми значениями баллов детей из замещающих прародительских семьях с воспитанниками из полных семей при любом стиле воспитания. Превалирование 31 в замещающих прародительских либеральных семьях может быть объяснено наличием более тесной эмоциональной связи и более доверительными отношениями детей с бабушками, нежели чем с мамами [12]. Прародители чаще хвалят своих воспитанников, помогают заниматься уроками и делами, организуют разнообразный досуг. Эмоциональная поддержка в совокупности с разносторонним планированием и осуществлением деятельностных процессов позволяет развивать более высокий уровень саморегуляции у детей в замещающих прародительских семьях по сравнению с детьми из полных и неполных семей. На втором этапе эмпирической части работы исследовались гендерные различия в уровне саморегуляции у детей из прародительских замещающих семей при авторитетном и либеральном стиле воспитания. Полученные результаты представлены на рисунке 16. При авторитетном стиле воспитания девочки демонстрируют более

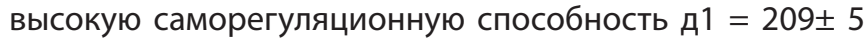
по сравнению с мальчиками м1 = 191士 6. В либеральных семьях распределение баллов существенно изменяется и девочки показывают более низкую способность к саморегуляции д2 = 155 5 относительно мальчиков м2 = $173 \pm 3$, однако оба случая соответствуют низкой саморегулятивной способности.

Результаты опроса могут быть объяснены различной степенью ориентации мальчиков и девочек на такие качества как послушание, активность, самостоятельность и планирование. При авторитетном стиле воспитания в среднем девочки более ответственно подходят к реализации задач и уделяют больше внимания планированию [6]. Мальчики же зачастую действуют импульсивно и показывают некритичность к своим действиям, что и отражается в меньшем уровне саморегуляции. Нетипичным результатом является то, что при либеральном стиле воспитания в замещающих прародительских семьях уровень саморегуляции мальчиков выше, чем у девочек. Объяснение такой особенности является предметом дальнейших исследований.

Таким образом, полученные в данной работе результаты показывают, что бабушки и дедушки способны довольно эффективно справляться с воспитанием детей. Это подтверждается тем, что средний показатель уровня саморегуляции воспитанников из прародительских семей занимает промежуточное положение между соответствующими значениями сверстников из полных и неполных семей. При этом важно также учитывать стиль воспитания в семье и гендерную принадлежность ребенка.

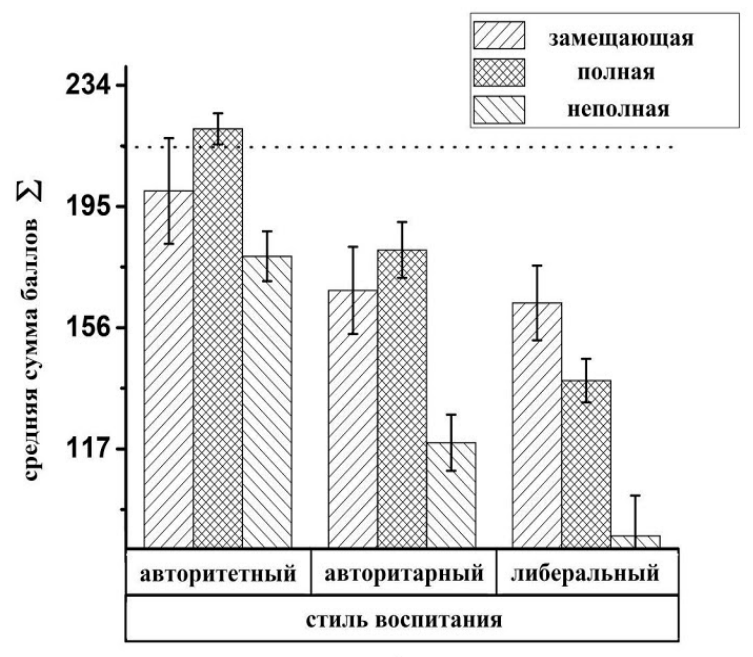

a)

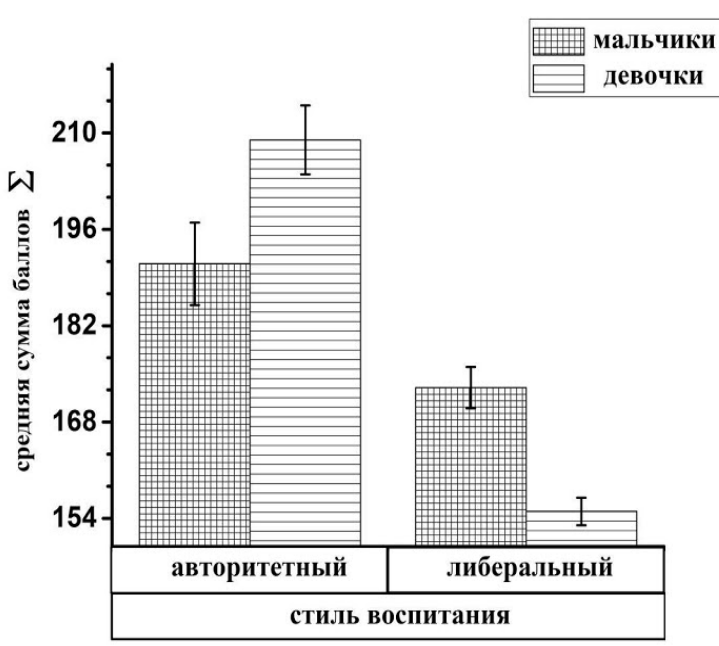

б)

Рис. 1. а) Распределение средней суммы баллов $\Sigma$ детей, воспитываемых в замещающих прародительских, полных и неполных семьях с различными стилями воспитания. Пунктирная линия соответствует пороговому значению баллов среднего сред.=214 уровня саморегуляции; б) Значения средней суммы баллов $\Sigma$ мальчиков и девочек, воспитываемых в замещающих прародительских семьях при авторитарном и либеральном стиле воспитания. 


\section{ЛИТЕРАТУРА}

1. Вербианова 0.М. Влияние стиля семейного воспитания на развитие саморегуляции детей 6-7 лет // Вестник КГПУ им. В.П. Астафьева. 2017. №1.(39). C. 129-333.

2. Кисова В.В. Формирование саморегуляции как компонента психологической подготовки к школьному обучению у старших дошкольников // Фундаментальные исследования. 2013. №8-4. С. 965-969.

3. Rosanbalm K.D., Murray D.W. Promoting Self-Regulation in Early Childhood: A Practice Brief. Washington, DC: Office of Planning, Research, and Evaluation, Administration for Children and Families, US. Department of Health and Human Service, 2017. Available at: https://fpg.unc.edu/node/9396 (accessed 28 May 2020).

4. Whitebread D., Basilio M. The emergence and early development of self-regulation in young children. Cambridge University Press. Psychology, 2012. Available at: https://www.ugr.es/ recfpro/rev161ART2en (accessed 28 May 2020).

5. Вербианова 0.М. Развитие способности к саморегуляции детей дошкольного возраста в социальном пространстве семьи // Вестник КГПУ им. В.П. Астафьева. 2015. №2(32). С. 184-188.

6. Кузьмишина Т.Л. Особенности эмоционального взаимодействия дошкольника с прародителями в современной семье // Ярославский педагогический вестник. 2014. №4. C. 249-253.

7. Baumrind D. The Influence of Parenting Style on Adolescent Competence and Substance Use. Journal of Early Adolescence, 1991, vol. 11, issue 1, pp. $56-95$. Available at: https://doi.org/10.1177/0272431691111004 (accessed 28 May 2020).

8. Brown J.M. Self-regulation and the addictive behaviors. In W. R. Miller \&amp; N. Heather (Eds.), Applied clinical psychology. Treating addictive behaviors. Plenum press, 1998, pp. 61-73. Available at: https://doi.org/10.1007/978-1-4899-1934-2_5 (accessed 28 May 2020).

9. Brown J.M., Miller W.R., Lawendowski L.A. The self-regulation questionnaire. In L. VandeCreek \&amp; T. L. Jackson, Innovations in clinical practice: A source book. Professional Resource Press, 1999, vol. 17, pp. 281-292. Available at: https://psycnet.apa.org/record/1999-02283-018 (accessed 28 May 2020).

10. Овчарова Р.В. Психология родительства: учеб. пособие для студ.высш. учеб. заведений. М.: Издательский центр «Академия», 2005.368 с.

11. Эйдемиллер Э.Г. Методы семейной диагностики и психотерапии. Методическое пособие. СПб.: Фолиум, 1996. 48 с.

12. Мамонова Е.Б., Черемисова И.В. Особенности проявления личностной саморегуляции мальчиков и девочек младшего школьного возраста // Вестник Мининского университета. 2016. №3(16). С. 21.

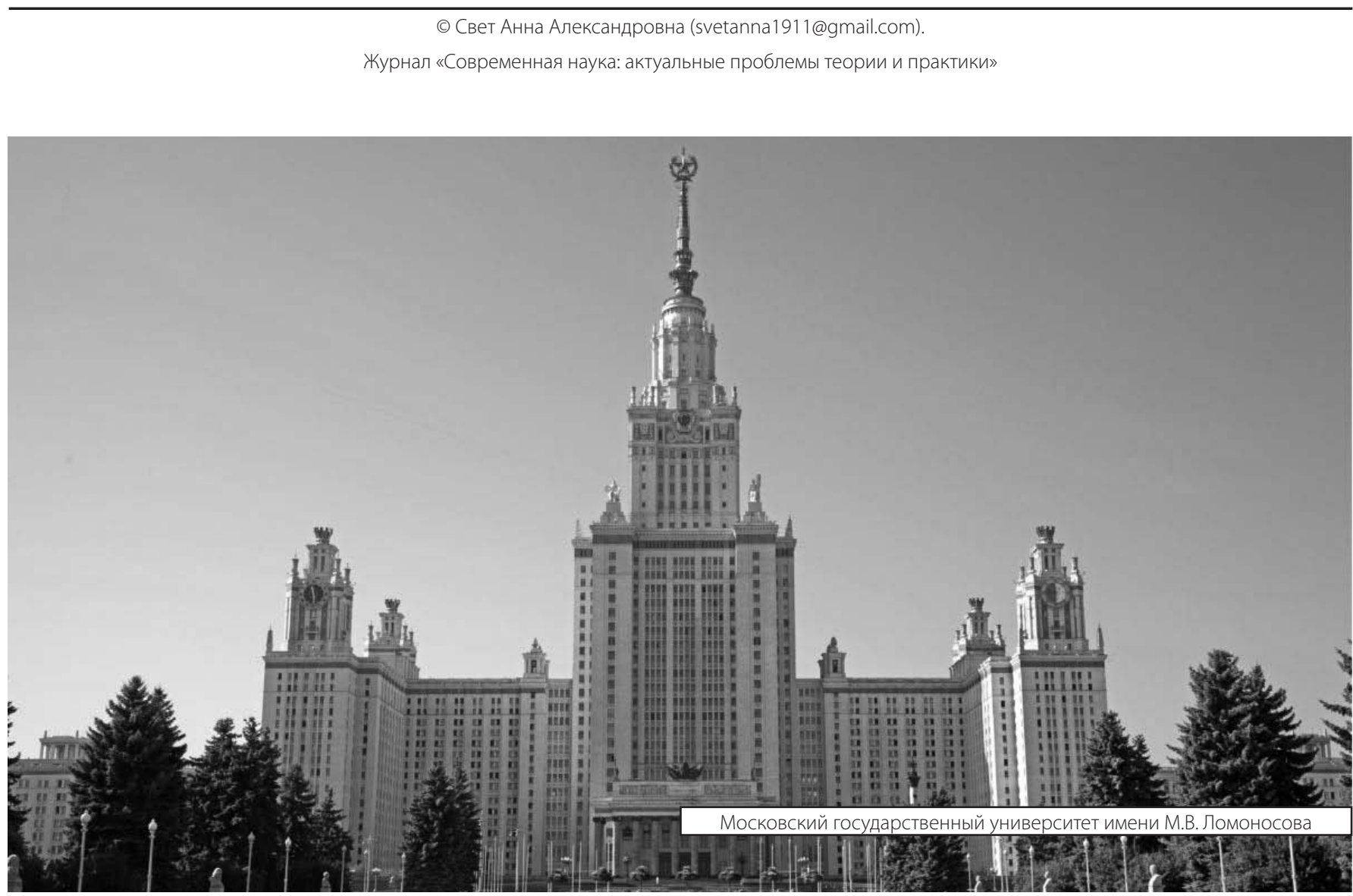

